\title{
RANCANG BANGUN SISTEM INFORMASI USAHA MIKRO KECIL MENENGAH STUDI KASUS DINAS KOPERASI UMKM DAERAH ISTIMEWA YOGYAKARTA
}

\author{
Annas Setiawan Prabowo'), Lutfi Syafirullah²) \\ 1) 2) Program Studi Teknik Informatika, Politeknik Negeri Cilacap \\ Jln.Dr.Soetomo No.1 Sidakaya 53212 Cilacap, Indonesia \\ annassetiawanp@gmail.com
}

\begin{abstract}
Abstrak
Kata Kunci:

data ; sistem

informasi; UMKM ;

waterfall,

Informasi tentang UMKM sangat dibutuhkan oleh Dinas Koperasi UMKM dalam menentukan arah pengembangan UMKM. Data yang akurat akan memberikan dampak yang tepat dalam menentukan program pengembangan serta pelayanan bagi pelaku UMKM. Permasalahan yang sering terjadi dalam mengelola data UMKM dan Konsultasi adalah pengelolaan masih dilakukan dengan cara manual menggunakan buku, sehingga resiko untuk kehilangan data, data ganda, serta pencarian data yang sulit ketika data dibutuhkan dengan cepat. Maka berdasarkan permasalah tersebut perlu adanya Sistem Informasi untuk mengelola data UMKM. Metode yang digunakan adalah metode pengembangan perangkat lunak waterfall. Hasil penelitian ini adalah sistem yang dapat mempermudah pengelolaan data, mempercepat proses pencarian data, menggolongkan menurut kriteria sehingga dapat dijadikan acuan dalam pengembangan dan pelayanan UMKM serta membantu konsultan dinas koperasi dalam proses konsultasi bisnis.
\end{abstract}

\section{Abstract}

Keywords: data; information

system, MSME;

Waterfall

\begin{abstract}
Information about UMKM is very much needed by the Cooperative Office of UMKM in determining the direction of MSME development. Accurate data will have the right impact in determining development programs and services for SMEs. The problem that often occurs in managing UMKM data and Consultation is that management is still done manually using a book, so the risk for data loss, double data, and data retrieval are difficult when data is needed quickly. So based on these problems it is necessary to have an Information System to manage MSME data. The method used is the waterfall software development method. The results of this study are systems that can facilitate data management, speed up the data search process, classify according to criteria so that it can be used as a reference in the development and service of MSMEs and assist cooperative service consultants in the business consultation process.
\end{abstract}

\footnotetext{
Alamat korespondensi :

E-mail : annassetiawanp@gmail.com

ISSN : 2087-1627
} 


\section{Pendahuluan}

Peran UMKM dalam perekonomian di Indonesia sangat penting. Menurut data kementrian Koperasi UKM dan BPS berdasarkan kriteria bahwa usaha skala kecil memiliki jumlah paling dominan yaitu $99 \%$. Hal tersebut tentunya memiliki makna bahwa hanya $1 \%$ saja usaha yang tergolong dalam skala menengah dan besar. Saat terjadi krisis ekonomi periode 1997 sampai 1998, hanya sektor UMKM yang mampu bertahan dari krisis. Data BPS menunjukkan bahawa setelah krisis ekonomi justru jumlah UMKM semakin naik, serta mampu menyerap 85 juta sampai 107 juta tenaga kerja pada tahun 2012 [1].

Yogyakarta memiliki beragam potensi perekonomian yang berkembang dengan cepat. Ekonomi yang dikembangkan oleh pemerintah daerah Istimewa Yogyakarta tergolong sebagai ekonomi kreatif. Hal tersebut diakerenakan potensi alam di Yogyakarta sangat terbatas, sehingga diperlukan kreatifitas dalam menjalankan usaha. Sektor UMKM. Pemerintah Daerah Daerah Istimewa Yogyakarta memiliki peranan penting dalam pengembangan UMKM agar pelaku usaha memiliki daya saing sehingga dapat bertahan dan mengembangkan usahanya. Pemerintah Daerah Istimewa Yogyakarta telah melakukan berbagai cara dalam meningkatkan daya saing UMKM melalui berbagai macam program. Program yang dilakukan oleh Dinas Koperasi UMKM selaku perpanjangan tangan dari Pemerintah Daerah Istimewa Yogyakarta diantaranya adalah dengan menumbuhkan wirausaha baru melalui pendidikan pelatihan, pendampingan, konsultasi bisnis, akses permodalan melalui Kredit Usaha Rakyat maupun Dana Bergulir. Sedangkan dari segi aspek pasar Dinas Koperasi UMKM telah memfasilitasi pameran baik di dalam maupun luar negeri serta memberikan fasilitasi pemasaran melalui media online dengan bekerjasama dengan pihak swasta maupun instansi lain [2].

Dinas Koperasi membutuhkan data UMKM yang akurat agar program pengembangan UMKM dapat berjalan dengan baik. Perubahan data yang cepat terutama di sektor Usaha mikro kecil menjadi kendala dalam update perkembangan jumlah serta kriteria UMKM. Masalah yang sering terjadi adalah pengelolaan data UMKM dan data konsultasi masih menggunakan cara konvensional yaitu ditulis dalam buku, sehingga beresiko kehilangan data, data ganda, serta kurang cepat dalam proses pencarian dan update data UMKM. Dengan adanya permasalahan tersebut maka perlu adanya sistemiInformasi UMKM untuk membantu Dinas Koperasi UMKM dalam mengelola data yang digunakan sebagai dasar dalam program pengembangan UMKM di Daerah Istimewa Yogyakarta. Tujuan penelitin ini adalah membuat Sistem Informasi UMKM untuk memudahkan
Dinas Koperasi UMKM Daerah Istimewa Yogyakarta dalam mengelola data UMKM dan menggolongkan sesuai dengan kriteria sehingga proses pengelolaan data UMKM menjadi lebih cepat, tepat dan akurat. Selain itu sistem ini mampu membantu konsultan dinas koperasi dalam proses konsultasi bisnis.

\section{Tinjauan Pustaka}

Penelitian yang dilakukan oleh Mardainis (2015) mengenai Sistem Informasi Usaha Mikro Kecil dan Menengah pada Dinas Koperasi Kota Pekanbaru. Meningkatnya usaha mikro, kecil dan menengah secara langsung akan meningkatkan perekonomian masyarakat. Banyaknya usaha mikro kecil dan menengah yang perlu untuk didata membuat sulit bagi dinas koperasi UKM untuk membuat laporan yang dibutuhkan secara cepat, sementara pertambahan data UKM sangat cepat. Jika data tidak up to date maka akan mempersulit mendapatkan data akurat. Untuk mengatasi hal tersebut maka dibutuhkan sistem komputer untuk membantu dalam pendataan umkm. Sistem yang dikembangkan berbasis desktop. Hasil dari penelitian ini adalah sistem informasi usaha mikro kecil dan menengah pada dinas koperasi kota Pekanbaru. Sistem ini memberikan informasi data usaha mikro, kecil dan menengah perjenis usaha, perdaerah serta per kelompok usaha. Sistem ini masih menggunakan desktop sehingga akses hanya bisa dilakukan di kantor dinas setempat [3].

Penelitian yang dilakukan oleh Nisfu Mahdayani, Haeruddin, Ummul Hairah (2017) tentang sistem informasi usaha mikro kecil menengah (UMKM) Kota Bontang berbasis website. Pengenalan masyarakat terhadap produk UMKM masih rendah yang disebabkan karena kurangnya promosi produk yang dihasilkan merupakan masalah klasik yang terjadi bagi para pelaku usaha selain itu dalam hal pendataan masih terkendala dengan sulitnya para pelaku usaha yang harus datang langsung untuk mendaftarkan usaha mereka. Sehingga upaya yang ditempuh adalah dengan melakukan pendataan langsung pada pelaku usaha untuk bisa mendapatkan data UMKM yang ada beserta hasil usahanya. Untuk membantu dalam memasarkan produk serta mengenalkan hasil produksi Kota Bontang kepada masyarakat dan juga untuk membantu dalam melakukan pendataan terhadap UMKM yang ada, diperlukan sebuah media yang dapat menginformasikan mengenai pelaku UMKM dan produk yang dihasilkan tanpa harus datang ke lokasi untuk lebih efektif dan efisien yaitu berupa sebuah Sistem Informasi. Dengan Sistem Informasi Usaha Mikro Kecil Menengah (UMKM) berbasis Website maka pelaku usaha dapat mendaftarkan diri beserta produknya kedalam sistem, sehingga Dinas Perindustrian dan Perdagangan dapat mendata pemilik UMKM beserta produknya dan memantau dari website. 
Sistem ini menggunakan bahasa PHP dan menggunakan database MYSQL. Hasil dari sistem yang dibangun yaitu menampilkan informasi UMKM beserta hasil produksinya [4]

Perbedaan penelitian ini dengan penelitian sebelumnya adalah sistem informasi yang dikembangkan berbasis website dengan memudahkan penyajian informasi berupa data UMKM berdasarkan kriteria usaha (Mikro, kecil, menengah), serta mengetahui sebaran data UMKM per kabupaten. Sehingga dengan adanya data UMKM yang tepat maka bisa dijadikan acuan dalam program pengembangan UMKM yang tepat sasaran.

\section{Metode Penelitian}

\subsection{Bahan Penelitian}

Penelitian dilakukan di Dinas Koperasi dan UMKM Daerah Istimewa Yogyakarta. Dari hasil penelitian, penulis mendapatkan fakta-fakta di lapangan berupa wawancara dan penulis juga melakukan pengambilan data berupa data pelaku usaha mikro kecil dan menengah (UMKM) serta proses pendataan UMKM oleh dinas koperasi UMKM. Data sekunder diperoleh dari studi literatur seperti junal dan buku.

\subsection{Tahap Pengembangan Sistem}

Metode yang digunakan dalam tahapan pengembangan sistem ini menggunakan metode waterfall [5]. Waterfall merupakan metode pengembangan sistem yang sistematis. Tahapantahapan waterfall disusun secara berurutan serta tidak ada tahapan yang berjalan secara bersamasama sehingga pengembangan sistem dapat diukur serta dapat memudahkan dalam proyek pengembangan sistem informasi. Metode air terjun (waterfall) sering juga disebut model sekuensial linier (sequential linear) atau alur hidup klasik (classic life cycle). Model air terjun menyediakan pendekatan alur hidup terurut mulai dari analisis, desain, pengodean, pengujian, dan pemeliharaan.

\subsection{Analisis Kebutuhan Sistem}

Analisis kebutuhan sistem sangat diperlukan agar sistem bisa dijalankan dengan baik. Dalam analisis kebutuhan diawali dari menentukan gambaran perangkat lunak yang akan dihasilkan dalam proyek pengembangan perangkat lunak. Perangkat lunak yang baik bukan perangkat lunak yang memiliki fitur canggih dan lengkap, namun perangkat lunak yang sesuai dengan kebutuhan pengguna. Selain itu perangkat lunak yang mudah digunakan oleh pengguna juga sangat dibutuhkan agar sistem yang dihasilkan dapat diterima oleh para pengguna sistem, tanpa mengalami kesulitan dalam pengoperasian sistem informasi.

Berdasarkan kebutuhan sistem pihak-pihak yang terlibat dalam penggunaan sistem dapat dilihat dalam tabel I.
TABEL I

ANALISA KENUTUHAN SISTEM BERDASARKAN PENGGUNA

\begin{tabular}{|l|l|}
\hline \multicolumn{1}{|c|}{ Pengguna } & \multicolumn{1}{|c|}{ Aktifitas } \\
\hline Super Admin & $\begin{array}{l}\text { Mengelola Admin, Mengelola } \\
\text { Konsultan, Mengelola Data } \\
\text { UMKM, Megelola Data konsultasi }\end{array}$ \\
\hline Admin & $\begin{array}{l}\text { Mengelola data UMKM, Rekap } \\
\text { data UMKM, Rekap Konsultasi }\end{array}$ \\
\hline Konsultan & $\begin{array}{l}\text { Lihat data UMKM, Mengelola } \\
\text { Konsultasi }\end{array}$ \\
\hline
\end{tabular}

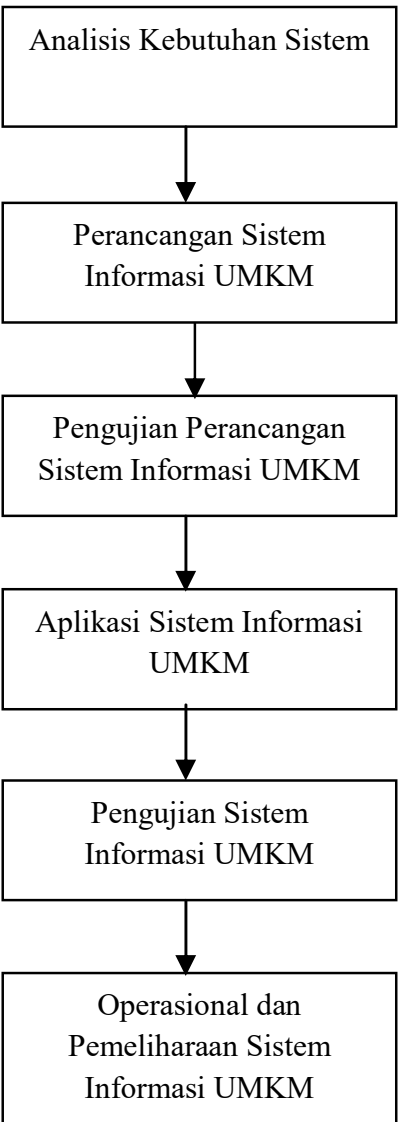

Gbr 1. Tahapan Penelitian dengan Metode Waterfall

\subsection{Perancangan}

Menurut Indra Griha Tofik Isa Unifed Modeling Language (UML) adalah keluarga notasi grafis yang didukung oleh meta-model tunggal, yang membantu pendekskripsian dan desain sistem perangkat lunak, khususnya sistem yang dibangun menggunakan pemrograman berorientasi objek [6]. 
Diagram yang akan dipakai adalah usecase untuk menggambarkan fungsi sistem dan class diagram untuk menggambarkan hubungan antar class.

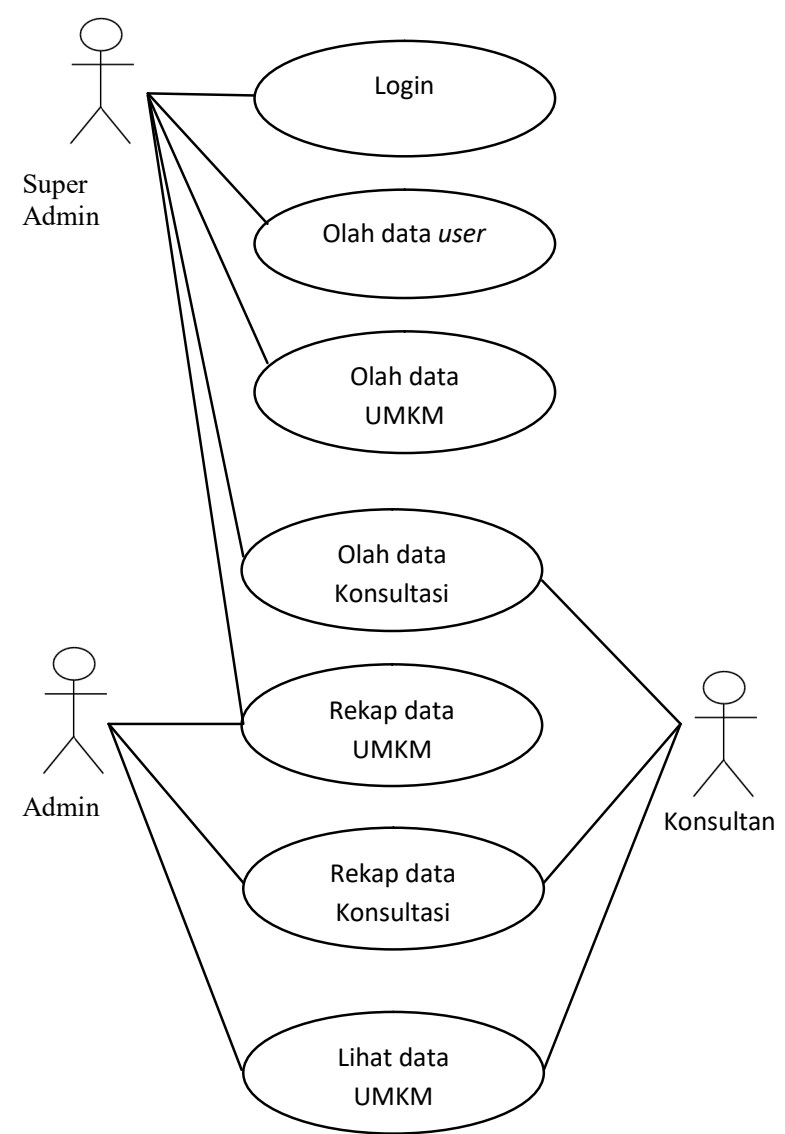

Gambar 2 Use Case Diagram

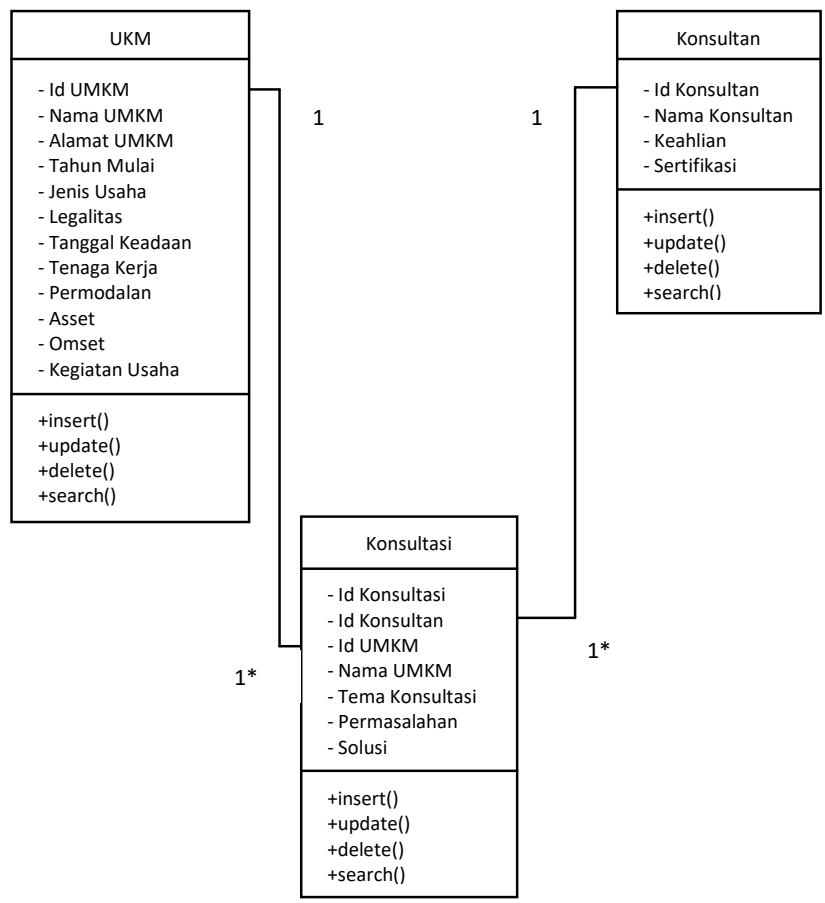

\section{Gambar 3 Class Diagram}

\section{Use Case Diagram}

Use Case diagram digunakan untuk menggambarkan sistem dari sudut pandang pengguna sistem tersebut (user). sehingga pembuatan use case diagram lebih dititik beratkan pada fungsionalitas yang ada pada sistem, bukan berdasarkan alur atau urutan kejadian. Sebuah use case diagram mempresentasikan sebuah interaksi antara aktor dengan sistem. Use case dalam sistem ini dapat dilihat pada Gambar 2.

\section{Class Diagram}

Class Diagram adalah spesifikasi yang akan menghasilkan objek dan merupakan inti dari pengembangan dan desain berorientasi objek. Class menggambarkan keadaan (atribut atau properti) suatu sistem, sekaligus menawarkan layanan untu memanipulasi keadaan tersebut (metode atau fungsi).

Kelas memiliki tiga area pokok:

a. Nama (Class Name)

b. Atribut

c. Metode (Operation).

Untuk Class Diagram pada sistem informasi usaha mikro kecil menengah dinas koperasi UMKM daerah istimewa Yogyakarta dapat dilihat pada gambar 3 .

\section{Hasil dan Pembahasan}

4.1 Hasil Penelitian

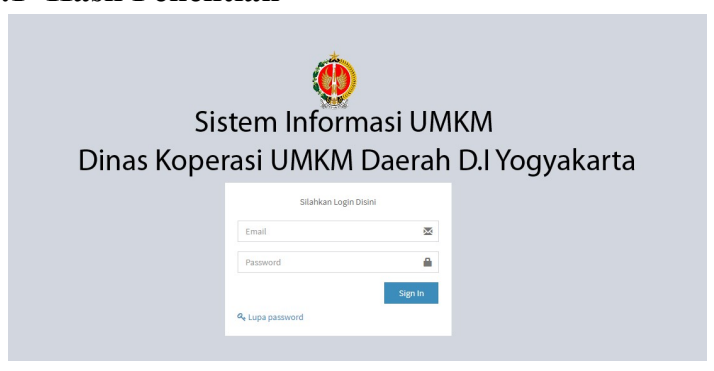

Gambar 4 Login User

Gambar 4 merupakan proses login user baik super admin, admin maupun konsultan. Proses ini akan menentukan hak akses masing-masing user. Jika memasukan user dan password yang salah maka tidak akan masuk sistem, sebaliknya jika username dan password benar maka akan bisa masuk ke dalam sistem. 


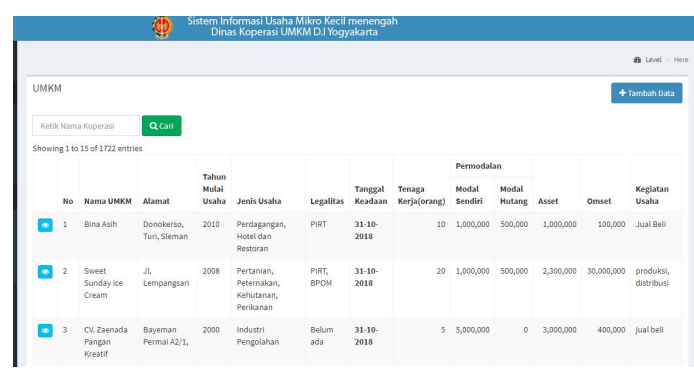

Gambar 5 Menu Admin Pengelolaan UMKM

Gambar 5 merupakan menu pengelolaan UMKM. Admin bisa mengelola data UMKM baik menambah, mengubah atau menghapus data sehingga data selalu up to date. Tanggal ketika menambah dan merubah data ditampilkan, sehingga akan memudahkan admin untuk mengetahui kapan terakhir data UMKM tersebut dirubah.

Menu pencarian memudahkan admin dalam mencari UMKM berdasarkan nama, alamat, omset, aset. Di sistem sebelumnya admin harus membongkar hard file untuk menemukan data, dengan sistem ini admin bisa mencari data sesuai dengan kriteria tertentu dengan waktu yang cepat. Rekap data juga akan semakin mudah dengan sistem tersebut.

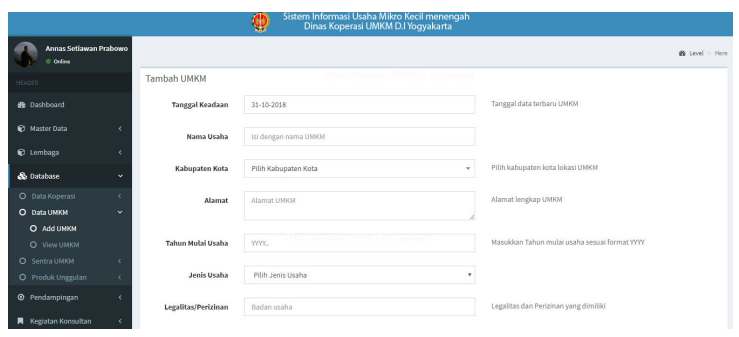

Gambar 6 Menu Tambah UMKM

Gambar 6 menunjukkan menu tambah umkm yang berfungsi menambah data umkm ke dalam sistem informasi. Jika data yang dimasukkan diisi semua maka data akan bisa masuk. Jika data yang dimasukkan ada yang kosong maka akan muncul pemberitahuan bahwa data harus diisi.

\subsection{Pembahasan}

Sistem informasi UMKM (Usaha Mikro Kecil Menengah) ini digunakan oleh Dinas Koperasi UMKM Daerah Istimewa Yogyakarta dengan beberapa pengguna yang bisa mengakses aplikasi yaitu admin, super admin, dan konsultan. Super admin memiliki hak akses dalam mengelola data umkm, mengelola user, mengelola konsultasi. Admin memiliki hak akses untuk mengelola UMKM, mengelola konsultan dan mengelola konsultasi. Konsultan memiliki hak akses dalam mengelola data konsultasi serta melihat informasi UMKM. Sistem Informasi ini dapat mempercepat proses pengelolaan data berupa input update dan delete. Proses pencarian data yang diinginkan berdasarkan nama, alamat serta kriteria menjadi semain cepat.

Proses rekap konsultasi akan menjadi semakin mudah. Konsultan akan semakin terbantu dengan adanya sistem ini karena mampu melihat history konsultasi yang dilakukan oleh pelaku UMKM. Sehingga konsultan akan bisa lebih tepat memberi solusi terhadap permasalahan usaha jika data yang disajikan lengkap dan terdokumentasi dengan baik.

\section{Kesimpulan}

Kesimpulan dari penelitian sistem informasi UMKM dapat memepermudah dalam pengelolaan UMKM diantaranya adalah pendataan UMKM secara up to date, memudahkan manajemen konsultasi serta mempercepat pencarian data UMKM dan penggolongan data UMKM sesuai dengan kriteria

\section{Daftar Pustaka:}

[1] Y. R. Suci, "Perkembangan UMKM ( Usaha Mikro Kecil dan Menengah ) Di Indonesia," J. Ilm. Cano Ekon., vol. 6, no. 1, pp. 51-58, 2017.

[2] Departemen Koperasi dan UMKM DIY, "Perkembangan Koperasi \& UKM DIY," 2018.

[3] Mardainis, "Perancangan Sistem Informasi Usaha Mikro Kecil dan Menengah pada Dinas Koperasi Kota Pekanbaru," $J$. Teknol. Inf. Komun. Digit. Zo., vol. 6, no. 1, pp. 17-24, 2015.

[4] N. Mahdayani, H. Haeruddin, and U. Hairah, "Sistem Informasi Usaha Mikro Kecil dan Menengah (UMKM) Kota Bontang Berbasis Website," in Prosiding Seminar Nasional Ilmu Komputer dan Teknologi Informasi, 2017, vol. 2, no. 2, pp. 110-116.

[5] R. Ariani and M. Shalahuddin, Modul Pembelajaran Rekayasa Perangkat Lunak. Bandung: Modula, 2011.

[6] I. G. Tofik Isa and G. Pri Hartawan, "Perancangan Aplikasi koperasi Simpan Pinjam Berbasis Web (Studi Kasus Koperasi Mitra Setia)," Ju r n a l I l m i a h I l m u E ko no $m i$, vol. 5, 2017. 